\title{
"Como se hace en Indias de Castilla". El cacao entre la Amazonía portuguesa y las Indias de Castilla (siglos XVII y XVIII) ${ }^{1}$
}

\author{
Rafael Chambouleyron \\ Universidade Federal do Pará (Brasil) \\ rafaelch@ufpa.br
}

Recepción: 17 de enero de 2104 / Revisión: 17 de marzo de 2014

Aceptación: 29 de abril de 2014 / Publicación: diciembre de 2014

\section{RESUMEN}

El objetivo de este artículo es investigar las razones por las cuales la corona portuguesa invirtió en el cultivo del cacao en sus posesiones septentrionales de América. El principal argumento del texto es que la importancia creciente del cacao para Portugal fue resultado de una relación entre lo que podríamos llamar de "herencia" castellana en el mundo portugués, una serie de circunstancias económicas de la producción y comercio del cacao en el mundo hispánico y el proceso de "atlantización" de las conquistas portuguesas.

Palabras clave: Amazonía portuguesa, cacao, Indias de Castilla, Brasil, siglos XVII y XVIII.

\section{"Como se hace en Indias de Castilla". Cocoa in the Portuguese Amazonia and the Castilian Indies (17 ${ }^{\text {th }}$ and $18^{\text {th }}$ centuries)}

\begin{abstract}
The objective of this article is to study the reasons behind the Portuguese Crown's decision to invest in the cultivation of Cocoa in its northernmost American possessions. The main argument is that Portugal's growing interest in cocoa was the result of related factors, which include what we could call the Portuguese world's Castilian "heritage", the economic circumstances of cocoa production and commerce in the Hispanic world and the "Atlantization" of the Portuguese conquests.
\end{abstract}

Keywords: Portuguese Amazonia, Cocoa, Castilian Indies, Brazil, $17^{\text {th }}$ and $18^{\text {th }}$ centuries.

Sumario: 1. Introducción. 2. El Maranhão y El Brasil en la historiografía brasileña. 3. El Maranhão y Las Indias. 4. Encomenderos, traficantes y comerciantes. 5. El cultivo del cacao del Maranhão. 6. Conclusiones. 7. Referencias bibliográficas.

${ }^{1}$ Esta investigación cuenta con el apoyo del Conselho Nacional de Desenvolvimento Científico e Tecnológico $(\mathrm{CNPq})$ y de la Fundação para a Ciência e a Tecnologia (FCT). El autor agradece la lectura y comentarios de Alírio Cardoso, Ronald Raminelli, José Luis Ruiz-Peinado Alonso y Roberta Stumpf. 


\section{INTRODUCCIÓN}

A principios de los años 1660, un colono portugués llamado João Ornelas da Câmara le escribía un "papel" a la reina regente de Portugal, Doña Luisa de Gusmão. Ornelas da Câmara era natural del Estado del Maranhão y Pará, territorio administrativo de las posesiones portuguesas en Sudamérica creado en la década de 1620 y separado del llamado entonces Estado del Brasil. El territorio del antiguo Estado del Maranhão y Pará correspondía aproximadamente a la actual Amazonía brasileña. A lo largo del siglo XVII, la economía de esa región se consolidó a partir de la agricultura y de actividades de extracción de diversos productos de la selva ecuatorial (las llamadas "drogas do sertão"). Sobre ellos discurría Ornelas da Câmara. Era el caso del llamado "clavo del Maranhão", en realidad, corteza de un árbol cuyo gusto era similar al famoso clavo de la India. Escribía también sobre el urucú, del cual se podía producir tinta. Sobre la pita, "de la cual se hacen medias, casi como de seda, mantos y riendas". Sobre la abundancia de añil, "del cual se podrán sacar grandes intereses en este Estado [del Maranhão y Pará]". Finalmente, se refería al cacao, del cual "en aquellas partes" había "muchos árboles agrestes".

A lo largo de su texto, Ornelas da Câmara se refería a los varios productos de la región a partir de analogías con géneros de otras conquistas de Portugal y de Castilla. Sobre el "clavo del Maranhão", por ejemplo, explicaba cómo se podía aprovechar, a la similitud de los árboles de alcornoque (en Portugal) y los de canela en Ceilán. Del urucú, o achiote, del fruto se hacía una "masa que sirve para tintas", que se usaba en toda Europa, y que valía "6 a 7 tostones en España, 7 u 8 reales en Indias", donde la vio fabricar en casa de un portugués que vivía en la "ciudad de Cuba". Del mismo modo, decía, podía dar noticia de la fabricación de la "pita de Indias". Sobre el cacao, aludía a los "intereses que sacan los castellanos en las Indias y aduanas de España". En las Indias, en Caracas, relataba, había ya plantadores con 50 a 60.000 árboles de cacao. Incluso, se había informado sobre la producción del cacao en las "Indias" por donde anduvo por algún tiempo y también en la Isla de Trinidad ${ }^{2}$.

Escrito en un periodo relativamente próximo a los años finales del Portugal Habsburgo, parecía natural que Ornelas da Câmara se hubiese aprovechado de la circulación de conocimientos, ideas y rutas que la reunión de las coronas de Castilla y Portugal generó en un entonces vasto imperio ${ }^{3}$. La influencia de las experiencias coloniales castellanas es particularmente importante para entender el lugar que tuvo el cacao en la economía y sociedad del Estado del Maranhão, durante la segunda mitad siglo XVII. El objetivo de este artículo es investigar las razones por las cuales la corona portuguesa (ya separada de Castilla) invirtió en el cultivo del cacao en sus posesiones septentrionales de América. El principal argumento del texto es que la importancia creciente del cacao en el Estado del Maranhão fue resultado de una relación entre lo

\footnotetext{
2 Papel q. se deu a Rainha D Luiza sobre varias utilid. ${ }^{\text {es }}$ do Maranhaõ. S.1, c.1650. Arquivo Nacional da Torre do Tombo [en adelante ANTT], Coleção São Vicente, vol. 23, ff. 232-237.

3 Ver: Gruzinski, 2004; Cardoso, 2012. Ver también: Valladares Ramírez, 1993; Cardim, 2004. Sobre el Portugal Habsburgo, ver: Bouza Álvarez, 2000; Schaub, 2001. Sobre nuevos frentes de investigación en relación con la inserción de las conquistas americanas de Portugal en la Monarquía Católica, ver: SANTOS PÉREZ, 2012.
} 
que podríamos llamar de "herencia" castellana en el mundo portugués, una serie de circunstancias económicas de la producción y comercio del cacao en el mundo hispánico y el proceso de "atlantización" de las conquistas portuguesas.

Estudiada aquí a partir de la experiencia del cacao amazónico de la segunda mitad del siglo XVII, la relación entre el mundo portugués y castellano nos interesa particularmente como una posibilidad de reescribir la heterogénea historia del actual Brasil, a partir de otros puntos de vista, no solamente "brasileños" ni "portugueses", como ha insistido buena parte de la bibliografía que trabaja sobre la América portuguesa.

\section{EL MARANHÃO Y EL BRASIL EN LA HISTORIOGRAFÍA BRASILEÑA}

A lo largo del siglo XX, la historiografía sobre el Brasil colonial, por lo menos la que se refiere a la parte norte, construyó una explicación sobre la organización social y económica del Estado del Maranhão y Pará que, en gran medida, se basaba en la experiencia azucarera brasileña. Autores clásicos que escribieron historias generales del Brasil, durante la primera mitad del siglo pasado, como Celso Furtado, Caio Prado Júnior, Roberto Simonsen, Nelson Werneck Sodré y Arthur Cezar Ferreira Reis, entendieron que la incapacidad de desarrollo de una economía de "plantation" (tal cual se encontraba establecida en la región nordeste del Brasil) generó la implantación de una sociedad y economía volcadas hacía la selva amazónica, dependiente del trabajo indígena y básicamente de subsistencia ${ }^{4}$.

Esa perspectiva interpretativa, construida inicialmente por obras que buscaban una comprensión general de la formación del Brasil nacional, se desdobló en obras posteriores. A partir de la década de 1980, se habla de la región amazónica como periférica con relación al Estado del Brasil. Esa condición suponía la incapacidad de desarrollar una economía de exportación y su débil integración a los circuitos comerciales y atlánticos que caracterizaban la economía de la América portuguesa ${ }^{5}$. Recientemente, Antonio Filipe Pereira Caetano retomó el debate, argumentando que la economía azucarera constituyó un modelo y referencia para las conquistas, incluso para el Estado del Maranhão y Pará. Caetano ve en la región amazónica el embate entre dos proyectos, el azucarero y el de las "drogas do sertão", este último vencedor'.

Interesa aquí mostrar cómo la interpretación de las especificidades de la región amazónica portuguesa, por parte de la historiografía brasileña, fueron pensadas principalmente a partir de las bases del Estado nacional. De hecho, los trabajos citados presuponen una unidad que no sólo es geográfica sino, más que todo, analítica. De ella se explica el propio fracaso y condición periférica de la región amazónica ${ }^{7}$.

El problema de ese tipo de perspectiva -y aquí no se trata de negar las relaciones entre las diversas conquistas portuguesas de América, como discutidas por los auto-

4 Prado Júnior, 1987, pp. 69-70; Furtado, 1987, pp. 66-67; Simonsen, 1937, pp. 110-147; Sodré, 1964, pp. 128-129; REIS, 1993, pp. 91-96.

5 Ver, principalmente: CARdoso, 1984, pp. 94-104; Schwartz, 1998, pp. 384-402; AlenCASTRo, 2000 , pp. $58-59$ y $139-143$.

6 Caetano, 2011.

7 Ver: RicCI, 2003. 
res citados- es que establece una jerarquía interpretativa. Más todavía, la centralidad de los límites del Estado nacional nos impide en gran medida percibir otras conexiones que daban sentido a la construcción del mundo colonial amazónico e, incluso, a la construcción de las relaciones entre europeos y pueblos que no estaban sometidos al dominio colonial.

Ya hace algunos años, la historiografía brasileña viene mostrando la necesidad de establecer los lazos con otras experiencias coloniales para entender el desarrollo de la economía y de la sociedad del Estado del Maranhão y Pará. Es el caso de los vínculos con el Oriente, que en gran medida dictaron una primera mirada sobre varios productos forestales amazónicos, que fueron pensados inicialmente como substitutos de las especias orientales ${ }^{8}$. O de las fronteras de la Amazonía que conectaban indios, africanos, portugueses, castellanos, franceses y holandeses ${ }^{9}$. Es seguramente el caso del cacao, que principalmente a partir de la década de 1650, empieza a aparecer en los informes de los colonos y autoridades, y comienza a interesar cada vez más a la corona portuguesa. Para entender el cacao en la Amazonía portuguesa, la dicha condición periférica del Estado del Maranhão y Pará con relación al Brasil de poco nos sirve. Nuestra mirada tiene que dislocarse en dirección a las conquistas castellanas de América. Dos caminos nos interesan particularmente. Primero, el que conectó la "conquista" del Maranhão y Pará a las Indias castellanas, principalmente a lo largo de las primeras décadas del siglo XVII. Segundo, el que conectó las regiones productoras y consumidoras de cacao (en Venezuela y Nueva España) al mundo portugués, en el mismo periodo.

\section{EL MARANHÃO Y LAS INDIAS}

En 1645, el doctor Mateus de Sousa Coelho, vicario-general del Estado do Maranhão e Pará, recibía orden del Santo Oficio de la Inquisición de Lisboa para "repreguntar" las personas que habían denunciado a Salvador Saraiva, las cuales tenían que ratificar su testimonio. El crimen de Saraiva era que

siendo casado primera vez en la forma del sagrado Concilio Tridentino con Catarina Fróis, y siendo esta viva, en la ciudad de Caracas de Indias de Castilla, se casó segunda vez con Leonor de Oliveira, convertida, en la misma forma del sagrado Concilio Tridentino $^{10}$

En la primera serie de testimonios, el alguacil Manuel Carvalho declaraba que Salvador Saraiva era "hombre de mala vida y costumbres", que siendo casado con Catarina Fróis, la maltrataba y, después de mandarla "para Indias", estando ella viva,

\footnotetext{
8 Ver: Chambouleyron, 2007 y 2010, pp. 153-154; Cardoso, 2010. Ver también: Lapa, 1973; Almeida, 1995.

9 Ver: Acevedo Marin - Gomes, 2003; Guzmán, 2006; Gomes, 2011; Hulsman, 2011; Ruiz-Peinado Alonso, 2012.

10 Denuncia contra Salvador Saraiva. 1645. ANTT, Inquisição de Lisboa, Cadernos do Promotor, livro 231, ff. $257-257 \mathrm{v}$
} 
se había casado con Leonor de Oliveira. Lo mismo relataba Mateus Nunes, ayudante reformado, que confirmaba que Saraiva se casó con Leonor después que su primera mujer "se embarcó para Indias". El testigo siguiente, Álvaro Teixeira, también ayudante, añadía algunos detalles que nos interesan. No solamente confirmaba la misma historia y que Catarina vivía "en Indias en la ciudad de Caracas", sino que sabía de ello "por estar en la dicha ciudad algunas veces, en su casa, y ser ella comadre de él, testigo". Otro soldado, Tomás Guilherme, también había visto a Catarina Fróis en Caracas, "donde él, testigo, estaba". Después de "él, testigo, venir al Maranhão", decía Tomás Guilherme, se casó Saraiva con Leonor. Bartolomeu Rodrigues explicaba que Leonor de Oliveira era "una convertida de las que trajo Bento Maciel", lo que confirmaban Bartolomeu de Sá y varios otros testigos. Ya Gaspar Gonçalves Cardoso declaraba saber de la historia "por estar en la dicha ciudad de Caracas cerca de un año"; allí había encontrado a Catarina la cual le contó "que se descasara de su marido" 11.

Como se puede ver por los testimonios, había una circulación posible entre el Maranhão y la ciudad de Caracas, cuya existencia se debió a la unión de las dos coronas, periodo en el cual o próximo del cual ocurren los sucesos relacionados al bígamo Salvador Saraiva. Esa circulación entre las Indias y el Maranhão se hace también sentir en documentos posteriores, que discuten el lugar de los castellanos o de los portugueses en Indias, después de la Restauración.

Algunos años después del fin de la unión dinástica, por ejemplo, el Consejo Ultramarino discutía el caso de Francisco de Andrade, el cual, "ausentándose para las Indias de Castilla", había dejado tierras y esclavos indígenas. Los bienes habían sido dejados a los religiosos franciscanos, quienes finalmente pasaron su administración a Domingos Portilho, años antes, en 1642. Diez años después, el rey decidía que el capitán-mayor del Pará debía usar los bienes de los "ausentes en Castilla" (léase aquí, también ausentes en Indias), lo que contrariaba los intereses de los religiosos y de Domingos Portilho. El Consejo incluso advertía que se trataba de "ausente que estaba en Indias antes de la aclamación de V.M." ${ }^{12}$. Pocos años antes, en 1649, el propio Consejo había declarado ser "misericordia del cielo" el hecho de que, faltando rentas para pagar la infantería, se había conseguido recaudar considerables sumas de haciendas de dos "vecinos de Madrid" y de un "ausente en Castilla"13.

La propia fundación y ubicación del Estado del Maranhão y Pará no sólo se había hecho durante la unión de las coronas, sino que, a lo largo de las primeras décadas del siglo XVII, su lugar se pensaba también como de conexión entre las viejas conquistas de Portugal y de España. Recientemente, algunos trabajos han tratado de reexaminar el lugar del Estado del Maranhão y Pará en el contexto de la Monarquía dual.

Las tesis doctorales de Guida Marques y Alírio Cardoso, justamente, indican la íntima conexión entre la creación del Estado del Maranhão y Pará y la Monarquía Hispánica. No se trata de una mera coincidencia temporal. Para ambos autores, la

\footnotetext{
11 Ibídem, ff. 258, 258v, 259v, 260v, 261, 261v, 266v.

12 Consulta del Consejo Ultramarino. Lisboa, 3 de julio de 1656. Arquivo Histórico Ultramarino [em adelante AHU], Maranhão (Avulsos), caixa 4, doc. 385.

13 Sobre o q. escreve Luis de Magalhães gov. ${ }^{\text {or }}$ do Maranhaõ, açerca do dr. ${ }^{\circ}$ q. aly se tomou pertençente a absentes em Castella. Lisboa, 17-XII-1649. AHU, códice 14, f. 205. Sobre castellanos en tierras portuguesas de América durante la Unión Ibérica, y los problemas de identidad, ver: VILARDAGA, 2010, pp. 305-336.
} 
conquista de la región y la fundación de ese Estado es expresión de la Unión Ibérica ${ }^{14}$ y representa la puesta en marcha de mecanismos de expansión propios de la monarquía filipina, de manera que, como define Alírio Cardoso, "no se puede pensar la conquista del Maranhão fuera del contexto de la Monarquía Hispánica"15. Según este autor, incluso, el advenimiento de la nueva dinastía portuguesa, después de 1640, no significó una alteración radical en los rumbos de esa nueva conquista, ya que las principales políticas del nuevo rey portugués para la región habían sido establecidas en el periodo anterior: expansión hacia el oeste, donación de tierras como forma de defensa y crecimiento económico, reconocimiento de las autoridades indígenas, control de los nativos por medio de una política misionera ${ }^{16}$.

Más todavía, como muestran Marques y Cardoso, las Indias de Castilla representan en varios momentos un término de comparación para pensar la conquista y organización de la colonización del Estado del Maranhão y Pará. Como señaló ya Serge Gruzinski, la propia existencia de la Monarquía Hispánica pone en relación "espacios de circulación, intercambios y enfrentamientos" ${ }^{17}$. Con relación al Maranhão y Pará, durante la unión dinástica, esas relación se concretizó, principalmente, en dos esferas. Por un lado, la conexión atlántica del Maranhão y Pará, que acompaña un movimiento general de transferencia de los intereses comerciales de portugueses hacia el Atlántico y las conquistas castellanas ${ }^{18}$. Ya a partir de mediados de la década de 1610, hay una serie de propuestas de inserción del Maranhão y Pará en la ruta entre Perú y España, utilizándose la red fluvial amazónica y el Caribe. Ese proyecto sólo era posible ya que el Estado del Maranhão y Pará se insertaría como parte de la política castellana para la región amazónica ${ }^{19}$. En ese sentido, como indica la historiografía, la continuidad de la unión dinástica era una apuesta de varios grupos en el propio Maranhão y Pará, que se beneficiaban y se legitimaban frente a la corona castellana. De esa manera, la unión de las coronas era igualmente una tópica de la estrategia discursiva de los portugueses, incluso como forma de ascensión social y de obtención de privilegios ${ }^{20}$.

Por otro lado, el intento de "importación" del modelo de gestión de la mano de obra indígena. De hecho, en los años 1620 a 1640, hay una serie de propuestas para establecer la encomienda como manera de garantizar el propio dominio de la conquista del Maranhão y Pará ${ }^{21}$. La encomienda "maranhense" era pensada como de servicio personal, lo que la aproximaba, significativamente, de la experiencia venezolana, incluso de explotación del cultivo del cacao, que duró hasta finales del siglo $\mathrm{XVII}^{22}$.

\footnotetext{
14 Marques, 2009, p. 285.

15 Cardoso, 2012, p. 45. Ver también: Marques, 2009, p. 311.

16 Cardoso, 2012, p. 322.

17 GruZinski, 2001, p. 116. Ver también: Silva, 2012.

18 Ver: Studnicki-Gizbert, 2001.

19 Marques, 2009, pp. 317-319; Cardoso, 2012, pp. 199-214.

20 Marques, 2009, p. 299; Cardoso, 2012, p. 208.

21 Marques, 2009, p. 312; Cardoso, 2012, pp. 192-199.

22 Ferry, 1989, p. 68.
} 
Pero más allá del Maranhão y Pará y las conquistas castellanas de Sudamérica, había otras relaciones más globales que conectaban el mundo portugués y el mundo del cacao americano, como veremos a seguir.

\section{ENCOMENDEROS, TRAFICANTES Y COMERCIANTES}

A principios del siglo XVII, periodo que coincide con la conquista de la región amazónica por los portugueses (bajo la corona de Castilla), el chocolate era poco a poco asimilado en Europa y largamente consumido en Nueva España ${ }^{23}$. No hay duda que esa experiencia fue fundamental para el "descubrimiento" por parte de los portugueses de las posibilidades y potencialidades del cacao, ya en la segunda mitad del siglo XVII.

En el periodo colonial la producción del cacao estaba difundida por diversas partes de las Américas. El cacao ya era consumido en México y Centroamérica antes de la conquista, aunque por un grupo restringido de grupos sociales, y era oriundo de plantaciones establecidas tanto en la costa del Pacífico como del Atlántico ${ }^{24}$. A lo largo del siglo XVI, el chocolate se difundió entre las poblaciones indígenas y europeas de Nueva España (aunque con alteraciones en la forma de su consumo) lo que significó el desarrollo de las viejas áreas productoras y el aparecimiento de nuevas regiones de cultivo del cacao, principalmente en Centroamérica ${ }^{25}$. En el siglo XVII, aparecen nuevas regiones productoras, no sólo en Centroamérica, como el valle de Matina (principalmente a partir de mediados de siglo) ${ }^{26}$, pero también las dos regiones que se transformarán en las principales exportadoras de cacao para Nueva España y Europa, Guayaquil ${ }^{27}$ y Venezuela, que nos interesa particularmente aquí.

De hecho, como vimos, Caracas era textualmente citada por João Ornelas da Câmara en su informe a la reina. Sobre el cacao de Venezuela, escribía este colono:

En las Indias, en la ciudad de Caracas, hay hombre con 50 y 60 mil árboles de cacao, y bien se sabe el rendimiento de cada uno. Dan estos árboles fruto a cada mes, recogiéndose en la menguante, y las agrestes del Pará, cada año solamente, por incultas; asimismo, se entiende ser este tan bueno y más oleoso. El suplicante se informó en las Indias, donde estuvo algunos tiempos, derrotado del Pará para este reino; y en la isla de la Trinidad, en la cual estuvo, y donde hay muchos de estos árboles, tomó particular práctica de la de la cultura de ellas, del tiempo y forma en que se disponen y plantan, y del más beneficio que se les hace, que vio por muchas veces y se ofrece a ir practicar en el Pará ${ }^{28}$.

\footnotetext{
23 Arcila Farías, 1950, pp. 37-39; Braudel, 1979, pp. 213-214; Harwich, 1995; Ferry, 2006; Norton, 2006; FATTACCIU, 2012.

24 Bergmann, 1969; MacLeod, 2008, pp. 68-69.

25 MacLeod, 2008, pp. 70-79 y 80-95; Tous, 2011.

26 Para el siglo XVII, ver: Rosés Alvarado, 1982; MacLeod, 1996; MacLeod, 2008, pp. 330-340.

27 Para el siglo XVII, ver: Arcila Farías, 1950, pp. 249-278; León BorJa - SzÁszdi Nagy, 1964; HernáNDEZ JAIMES, 2008.

28 Papel q. se deu a Rainha D Luiza sobre varias utilid. ${ }^{\text {es }}$ do Maranhaõ. S.1, c.1650. ANTT. Coleção São Vicente, vol. 23, f. 234v.
} 
La historia de la producción y exportación del cacao venezolano durante la primera mitad del siglo XVII (sus primeros registros aparecen en $1607^{29}$ ) revela interesantes relaciones entre las regiones productoras (en Venezuela), el puerto de llegada del producto en Nueva España (Veracruz), el mercado consumidor (principalmente la ciudad de México) y el mundo portugués. Según Eduardo Arcila Farías, el comienzo del comercio entre Venezuela y México se dio en 1622, con el envío de algunas fanegas de cacao. Desde entonces, las relaciones comerciales se incrementaron, al punto de representar Nueva España, en el siglo XVII y parte del XVIII, "el único mercado importante de Venezuela". Las cifras comparativas entre la exportación de cacao a Nueva España y a la metrópoli, presentadas por el historiador venezolano, revelan la importancia del mercado novohispano para la economía caraqueña: de 1620 a 1650 se exportaron más de 35.000 fanegas a México, y sólo 289 a España. De 1651 a 1700, más de 320.000 a México, y poco más de 71.000 a España ${ }^{30}$. En ese sentido, como también argumenta Eugenio Piñero, la expansión de la producción del cacao (antes de los años 1720) se explica por el aumento de la demanda novohispana ${ }^{31}$.

Este hecho remite al problema de las razones por las cuales el cacao venezolano llegó tan rápidamente al mercado mexicano, dado, incluso, la existencia de tradicionales zonas productoras en Centroamérica. Para Robert Ferry, el éxito del cacao venezolano era consecuencia no sólo de la preferencia que tenían los consumidores por el cacao de Caracas, sino también de cómo se organizaba ese comercio. Según Ferry, los productores venezolanos conseguían un precio competitivo para sus granos en México y al mismo tiempo compraban africanos que trabajaban en sus cultivos de cacao. La hipótesis de Robert Ferry es que durante los primeros años del comercio de cacao de Venezuela con Nueva España ocurrió lo que llama de "ventaja inicial":

Los vecinos de Caracas cambiaban cacao por africanos a una tasa que permitía a los comerciantes de esclavos/mercaderes de cacao portugueses vender a precios más bajos que los comerciantes centroamericanos en Nueva España. Deseosos de vender su carga humana cuanto antes después de la travesía atlántica, los traficantes no necesitaban un gran margen de ganancia en Caracas, porque conseguían ganancias substanciales en México, con el cacao que obtenían con la venta de los esclavos. De esta manera, los caraqueños conseguían esclavos a un precio moderado y encontraban una salida para su cacao ${ }^{32}$.

No se trata aquí de discutir las formas de organización de la producción de cacao y su comercio entre Venezuela y México. Lo que nos interesa aquí son las implicaciones de la hipótesis desarrollada por Robert Ferry, que en artículo posterior, define como "íntima conexión forjada entre el comercio de esclavos africanos y el comercio transcaribeño de cacao" 33 . En los primeros años de exportación del cacao caraqueño a Nueva España esa conexión estaba atravesada por la presencia de portugueses.

\footnotetext{
29 FERrY, 1989, p. 45.

30 Arcila Farías, 1950, p. 53.

31 PiÑERO, 1988, p. 90.

32 Ferry, 1989, p. 48.

33 Ferry, 2006, p. 51.
} 
Según Robert Ferry, en 1607, varios de los encomenderos que cultivaban cacao y el factor de la trata de esclavos eran portugueses ${ }^{34}$. La unión de las dos coronas, a partir de 1580, permitió un significativo establecimiento de portugueses en las Indias de Castilla, ya estudiado por la historiografía. Por otro lado, desde finales del siglo XVI, los portugueses tenían el dominio de los asientos de esclavos para las Indias, incluyendo (aunque ilegalmente) los puertos venezolanos ${ }^{35}$. Muchos de esos comerciantes y algunos de los mercaderes que en México estaban involucrados en el comercio del cacao entre Caracas y Nueva España, eran conversos portugueses que, después de la restauración de la corona portuguesa, fueron duramente reprimidos por la Inquisición novohispana ${ }^{36}$.

De esa manera, los varios puntos de la trayectoria de los granos de cacao caraqueño estaban articulados de una manera o de otra al mundo portugués. Durante la primera mitad del siglo XVII, por lo tanto, gracias a la unión dinástica, los contactos de los portugueses con la producción y el comercio del cacao eran considerables. Podemos suponer que, por medio de esas relaciones, las potencialidades del cacao, sus formas de producción y comercio pasaron por oídos portugueses y fueron recibidas como herencia por la recién "restaurada" monarquía portuguesa, a partir de 1640. De la misma manera que la experiencia oriental portuguesa modeló una primera percepción sobre las especias de la Amazonía, la experiencia castellana del cacao fue fundamental para construir una "mirada" portuguesa sobre ese producto. La participación de portugueses en la producción, comercio y consumo de cacao, en Caracas y en Nueva España, indican conexiones posibles en ese proceso.

De hecho, el incentivo a la producción del cacao por parte de la corona portuguesa fue un aliento principalmente al cultivo, por medio del cual se practicaba la explotación del cacao en las Indias de Castilla. Claro está, como con relación a muchos otros productos que poco a poco iban siendo "descubiertos" por los portugueses, con el auxilio de los indios, que la explotación por el cultivo era un ideal varias veces explicitado en la Corte y sus Consejos. A mediados de los años 1650, por ejemplo, una noticia anónima explicaba cómo el sargento-mayor Felipe da Fonseca e Gouveia había recibido órdenes, en finales de los años 1640, para tratar de plantar el clavo de Maranhão ${ }^{37}$.

Más allá de una política de incentivo al cultivo, no cabe duda que el éxito del cacao venezolano (y "castellano" en general) dictó la lógica de la corona con relación al producto para la Amazonía portuguesa. La decisión en los años 1670 de promover el cultivo sistemático del cacao en la capitanía del Pará, tarea encargada precisamente a un castellano, revela claramente esa influencia.

34 FERRY, 1989, p. 55

35 Vila Vilar, 1973; Newson - Minchin, 2007; Wheat, 2009.

36 Hordes, 1982; FERrY, 2006.

37 Noticia del clavo del Maranhão. S.1, c.1656. AHU, Pará (Avulsos), caixa 2, doc. 105; Para o gov. ${ }^{\text {or }}$ do Maranhaõ. Enviar em quantidade as amostras de cravos e noses moscadas. Lisboa, 14-V-1650. AHU, códice 275 , f. $167 \mathrm{v}$. 


\section{EL CULTIVO DEL CACAO DEL MARANHÃO}

En las décadas de 1650 a 1670 se configuró una coyuntura favorable que puede ayudar a entender el estímulo de la corona a la producción del cacao en el Estado del Maranhão y Pará. Esa coyuntura se desarrolla en varios escenarios.

Por un lado, la producción venezolana sufría terribles reveses. En primero lugar, los cacaotales fueron devastados por una plaga, la alhorra. A principios de los años 1640, un terremoto dejó a Caracas en ruinas. Finalmente, la producción de plata de las minas de Zacatecas entró en crisis, afectando los precios del cacao venezolano ${ }^{38}$. Añade Robert Ferry que la drástica caída de precios del cacao venezolano (casi cinco veces, entre finales de los años 1640 y mediados de la década siguiente) tiene que ser entendida a partir del mercado novohispano y la retomada de la producción del cacao ecuatoriano. A eso se tiene que sumar la persecución a los conversos en Nueva España, que ayudó a desestructurar el comercio con Caracas ${ }^{39}$. En ese periodo, justamente, ingleses, holandeses y franceses inician experimentos de cultivo del cacao en sus colonias caribeñas, aunque sin gran éxito ${ }^{40}$.

Significativamente, por esa época, las noticias sobre el cacao en el Estado del Maranhão y Pará empiezan a hacerse más frecuentes, señal que la experiencia de las Indias circulaba en los espacios de la Monarquía Hispánica, incluso, después de su fin. Ya a finales de la década de 1630 y principios de la siguiente, los portugueses tenían contacto con el cacao amazónico. El relato del jesuita Cristóbal de Acuña, publicado en 1641, se refiere a la abundancia del cacao en el río Amazonas, del cual "están sus orillas tan llenas". Apreciado "en la Nueva España y en donde quiera que saben que es chocolate", aclaraba, cultivado era de tanto provecho que cada árbol generaba de renta anual, "horros de todos gastos", 8 reales de plata ${ }^{41}$. Nuevamente, era el consumo "castellano", o mejor, novohispano, que servía de lente para dar un sentido a la explotación del cacao. Por más que la circulación del texto de Acuña haya sido controlada por la corona de Castilla, temerosa con la rebelión de los portugueses, como indica Dauril Alden, el cura no viajó solo ${ }^{42}$. El padre acompañaba al capitán Pedro Teixeira en su viaje de vuelta de Quito a Belém, lo que nos permite suponer algún intercambio entre castellanos y portugueses durante la expedición.

El hecho es que a partir de los años 1650, las noticias sobre el cacao son más frecuentes. En 1653, Duarte Ribeiro de Macedo, uno de los más importantes pensadores económicos del siglo XVII portugués, escribía sobre los varios géneros para el comercio que se habían descubierto en la región amazónica portuguesa. Entre ellos figuraba el cacao, sobre el cual discurría:

Del cacao considero lo mismo, y juzgo de mayor utilidad el manso [i.e. cultivado], en razón de los muchos gastos que se hacen con la cosecha y transporte del bravo [i.e.

\footnotetext{
38 Harwich, 2005, pp. 17-18. Infelizmente, nos fue imposible consultar la obra de ArCILA Farías, 1946.

39 FERRY, 1989, pp. 59-63.

40 Alden, 1976, pp. 110-113.

41 ACUÑA, 1641, ff. 14v-15.

42 Alden, 1976, p. 114; Cardoso, 2012, pp. 339-42; Livi Bacci, 2012, pp. 108-109.
} 
silvestre] por los ríos que corren, y la inseguridad de la cosecha, en el cual siempre se arruina $^{43}$.

Poco tiempo después, en una noticia del padre jesuita João de Soutomaior sobre una misión al río Pacajá, en 1656, se hablaba de los "bosques llenos de cacao", próximo al pueblo de Cametá, en el río Tocantins ${ }^{44}$. En los años 1660, el oidor Mauricio de Heriarte escribía una larga descripción del Estado del Maranhão y Pará, en la cual abundaban referencias al cacao. Según Heriarte, en las proximidades de la ciudad de Belém, "hay mucho cacao", que los portugueses no sabían "beneficiar". Situación grave, ya que para el magistrado, lo que nos interesa aquí particularmente, el cacao era "el mejor contrato que hay en las Indias de Castilla". Siguiendo su relato, destacaba que también en la isla de Joanes (hoy isla de Marajó), no les faltaba a los indios "maíz y mandioca, algodón, pita, urucú, mucho cacao y grandes maderas". En las tierras entre Cametá y la fortaleza de Gurupá, en los ríos Tocantins y Amazonas, decía Heriarte, se podían hacer "grandísimas haciendas", como ingenios y "plantas de cacao". Ya en el Río Negro y en el Amazonas, según el oidor, se podían hacer ingenios, plantar caña, tabaco y "otras drogas", como el cacao ${ }^{45}$. Ya a finales de los años 1660, el cacao era explotado por los portugueses, principalmente recogido en el interior -el sertão. Su importancia estaba no solamente en el envío de cacao a Portugal, sino también en el hecho que, poco a poco - tal cual había ocurrido en diversas partes de las Indias de Castilla (incluso antes de la llegada de los europeos)- los portugueses pasaron a usar el cacao como moneda en la región.

A partir de mediados de los años 1670, justamente cuando la producción venezolana gana nuevo aliento, la corona portuguesa empieza a invertir seriamente en el cultivo del cacao. Ese escenario más propio del mundo portugués se origina por un lado en los procesos de consolidación de la nueva dinastía, y por otro, en una serie de medidas económicas para, frente a una crisis más general del imperio, desarrollar las actividades económicas de sus colonias, principalmente americanas (incluso en el Estado del Maranhão y Pará), determinando un viraje del eje central del mundo portugués hacia el Atlántico ${ }^{46}$.

Con relación al cacao, la experiencia castellana fue base fundamental para la acción. A modo de ejemplo, en una carta al gobernador del Estado del Maranhão y Pará, el príncipe regente Don Pedro $\mathrm{II}^{47}$ ordenaba claramente que "las plantas de cacao, clavo y vainillas vayan en crecimiento, y se reduzcan y cultiven, como se hace en Indias de Castilla", ya que cultivadas, "será de mejor efecto y rendimiento"48.

43 Discurso sobre os generos p. $^{\mathrm{a}}$ o comercio que há no Maranhão e Pará. 1653. ANTT, Manuscritos do Brasil, $\mathrm{n}^{\mathrm{0}}$ 108, f. 23v.

44 "Diario da jornada que fiz ao Pacajá, anno 1656", codex CXV/2-11, fls. 66-73v. Diario da jornada que fiz ao Pacajá, anno 1656. Biblioteca Pública de Évora. Évora, Portugal, códice CXV/2-11, f. 73v.

45 Heriarte, 1874 (años 1660), pp. 24, 26, 29, 47. Y las noticias seguían, a medida que el texto describe las tierras subiendo el Amazonas. Ver, pp. 48, 51, 56 y 69.

46 Alencastro, 2000.

47 Don Pedro II fue regente entre 1667 y 1683; fue rey de 1683 a 1706.

48 P. ${ }^{\text {a }}$ o g. ${ }^{\text {or }}$ do Estado do Maranhaõ. Sobre a chegada de Marçal Nunes da Costa a capitania do Pará. Lisboa, 3-IV-1675. AHU, códice 268, ff. 9v-10. 
Algunos autores han indicado que los jesuitas fueron pioneros del cultivo y explotación del cacao en la región amazónica ${ }^{49}$. Según el padre Serafim Leite, los primeros intentos fueron hechos por el jesuita João Felipe Bettendorff, que, en 1674, habría transportado semillas del cacao de la capitanía de Pará para la capitanía de Maranhão, donde distribuyó los frutos de los primeros árboles entre los colonos. Este primer "evento auspicioso" habría llevado la corona a incentivar el cultivo ${ }^{50}$. Por lo que parece, los jesuitas fueron los primeros a plantar el cacao en la isla de São Luís, capitanía de Maranhão, de donde, además, el producto no era nativo ${ }^{51}$. De todos modos, no hay duda que, como vimos, los reportes hechos por varios colonos fueron los que de hecho llevaron a la corona a estimular el cultivo. Es verdad que la corona reconocía, en agosto de 1678, en carta al gobernador, que ya "se había plantado algún [cacao], particularmente los religiosos de la Compañía" 52 . Pero poco tiempo después, el propio rey se refería a João Ornelas da Câmara como

La primera persona que dio principios a esas plantas [cacao] en esa capitanía [Pará] por tener de ellas mucha noticia adquirida en las Indias de Castilla, donde fue arribado, yendo de este reino ${ }^{53}$.

No es fortuito el hecho de que las primeras medidas sistemáticas tomadas por la corona portuguesa para incentivar el cultivo del cacao se hayan originado de un "papel" presentado, entre 1676 y 1677, por Don Fernando Ramírez, natural de Huelva ${ }^{54}$, que migró para Portugal con la Restauración. Justamente, el papel de Don Fernando era escrito en "obsequio y gratitud que se halló siempre, venido de Castilla a esta Corte, en la Majestad del señor rey Dom João, el cuarto" ${ }^{55}$. Nombrado proveedor de la Real Hacienda del Estado del Maranhão y Pará, Don Fernando ya había servido en la capitanía de Río de Janeiro como escribano de la aduana, de 1654 a $1665^{56}$. En su papel, Don Fernando explicaba que se había informado de "personas prácticas de aquel Estado" sobre los géneros y drogas que podían hacer "más rentosa y opulenta la Real Hacienda". De los varios productos que producía el Maranhão y Pará, "naturalmente y sin cultura", aclaraba, estaban la vainilla y el cacao. El cacao era tan abundante, según Ramírez, que aunque era "agreste" se vendía a "precios muy sólidos".

\footnotetext{
49 Leite, 1943, pp. 158-161; ALden, 1996, pp. 546-547; WalKer, 2007, pp. 85-89; Arenz, 2010, pp. 338341.

50 LeITe, 1943, pp. 158-159.

51 Confirmaçaõ de hũa legoa de terra [... o o g. ${ }^{\text {or }}$ Ign. ${ }^{\text {co }}$ Coelho da Silva do Coll. ${ }^{\circ}$ de N. ${ }^{a}$ S. da Luz do Maranham, que he a de Anindyba. 30-IV-1678. ANTT, Cartório Jesuítico, maço 82, n 17. Ver: Alden, 1976, pp. 114-115.

52 Para o governador do Maranhão. Planta de Cacao e Baonilha. Lisboa, 19-VIII-1678. Anais da Biblioteca Nacional, vol. 66 (1948), p. 46.

53 Para o governador do Maranhão. Sobre o mesmo. Lisboa, 13-I-1679. Anais da Biblioteca Nacional, vol. 66 (1948), p. 47.

54 "Huelva del reino de Castilla", dice una consulta del Consejo Ultramarino. Ver: Dom Fernando Ramirez pede satisfaçaõ de seus serviços. Lisboa, 28-IX-1674. AHU, códice 85, f. 83.

55 El papel de Don Fernando Ramirez, está anexado a: "Consulta del Consejo Ultramarino". Lisboa, 20IX-1677. AHU, Maranhão (Avulsos), caixa 5, doc. 614.

56 Dom Fernando Ramirez pede satisfaçaõ de seus serviços. Lisboa, 28-IX-1674. AHU, códice 85, f. 83.
} 
Más allá de la importancia y posibilidades del cacao, no hay duda que este género -tal cual los diversos productos que los portugueses fueron encontrando en la selva amazónica, principalmente, a partir de la segunda mitad del siglo XVII- también constituyó una elemento de las estrategias discursivas de los vasallos que buscaban adquirir el favor del rey ${ }^{57}$. En ese sentido, la "fuerza" del cacao también estaba en su potencialidad retórica, capaz de convencer a la corona, gracias a una coyuntura favorable al desarrollo de su explotación en la región. Don Fernando, que nunca había puesto sus pies en el Estado del Maranhão y Pará al momento en que presentaba su "papel" (aunque lo haría poco tiempo después), sabía aprovechar la capacidad de convencimiento del cacao, en beneficio propio, e incluso, su condición de "castellano" que, como veremos, daba más credibilidad a sus propuestas.

Volvamos al texto de Don Fernando, que estaba dividido en tres partes.

En la primera discurría sobre la "utilidad" del cacao y vainilla, que tenían mucha "saca para toda Europa y todavía para muchas partes de África". Su exportación era garantizada, ya que no había otro lugar que los produjese "más que en las Indias Occidentales", y todo lo producido era poco "para consumirse en España". Era la razón para que el príncipe buscara a toda costa estimular su cultivo, para que fueran al reino "flotas enteras de estos géneros", lo que permitiría la riqueza de los colonos, de la Real Hacienda, el aumento del comercio con el Estado del Maranhão y Pará, y su "población necesaria". Así se había visto "en el Brasil", con el cultivo de caña, y con los franceses en Barbados, "con sus azucares y tabacos". Del mismo modo se experimentaría en el Maranhão y Pará, ya que el rendimiento del cacao, "en las Indias de Castilla" era de una pataca por árbol a cada año; ya las vainillas se vendían en Indias a dos "vinténs", siendo mucho mayores y mejores las del Estado del Maranhão y Pará. Más todavía, explicaba, la producción de esos géneros, "es el medio más proporcionado para introducirse en Portugal mucha de la plata de España", no bastando en ella "lo que viene de las Indias". Así, el cacao y la vainilla no sólo se podrían consumir en el reino, pero también "conducirse y llevarse de el para los más de Europa".

En la segunda parte, Don Fernando Ramírez explicaba "el modo como se debe plantar" el cacao. Según el texto, "de dos maneras se plantan en las Indias los árboles de cacao". La primera la explicaba a partir de la "experiencia de un colono "curioso" de Santo Domingo, que en 1635 había mandado "buscar a Caracas" plantas de cacao. La segunda manera era "más fácil, de mayor provecho, como se usa en Caracas". También discurría sobre el tipo de tierras para el cacao, la manera de secar y beneficiar los granos y la cantidad de trabajadores necesarios.

En la tercera parte, hablaba sobre las formas de incentivar el cultivo entre los colonos del Maranhão y Pará. Explicaba que los hombres se dedicaban al trabajo por el "interés particular del aumento de la hacienda" y por el "crecimiento de la honra". De tal manera que sugería que el monarca distribuyese hábitos de las órdenes militares entre los que plantasen cacao, para que "con esperanza de esta honra, se animarán todos a plantar el dicho cacao". Después, argumentaba, aumentaría el número de cultivos, "por el provecho e interés que la experiencia les mostrará, y habrá entre

57 Ver: Chambouleyron, 2005; Cardoso, 2012, pp. 217-251. 
ellos emulación". Si así se hiciese, estaba convencido Don Fernando, el Estado del Maranhão y Pará tendría abundancia de cacao, y los colonos

reconociendo ellos palpablemente la importante ganancia, se desvelarán mucho en el aumento de este género, como sucedió en las Indias, que comenzando en nuestros tiempos el uso del chocolate, en poco espacio se vio el gran lucro que obtienen los labradores de aquellas partes de este género ${ }^{58}$.

El papel de Don Fernando y sus razones rápidamente animaron a la Corte. Examinando el texto, en septiembre de 1677, los procuradores de la Corona y de la Real Hacienda y el Consejo Ultramarino apoyaron las propuestas presentadas ${ }^{59}$. Pocos meses después, el príncipe ordenaba por una provisión, con base a la "representación" de Don Fernando, y en razón de la "gran conveniencia" que resultaría a la Real Hacienda y al "aumento" del Estado del Maranhão y Pará, "la agricultura de las plantas de vainilla y cacao", que

en la forma que apunta el dicho Don Fernando Ramírez vaya a practicar la agricultura de los dichos vainilla y cacao, y ejercitar su oficio, y que así él, cómo el gobernador, los deben mandar plantar y beneficiar ${ }^{60}$.

Para tanto, el monarca revocaba ley anterior que impedía que gobernadores y "más ministros de aquel Estado" pudiesen dedicarse a cualquier cultivo ${ }^{61}$. Esta anulación sólo se aplicaba al gobernador y proveedor, "para que a su ejemplo cultiven aquellos moradores estas plantas" ${ }^{62}$. Una serie de órdenes fue entonces enviada al Maranhão y Pará determinando el cultivo del cacao y vainilla ${ }^{63}$. Según Timothy Walker, órdenes

\footnotetext{
58 Dom Fernando Ramirez pede satisfaçaõ de seus serviços. Lisboa, 28-IX-1674. AHU, códice 85.

59 Consulta del Consejo Ultramarino. Lisboa, 20-IX-1677. AHU, Maranhão (Avulsos), caixa 5, doc. 614.

60 Ibidem.

61 En las décadas de 1640 y 1650, en varias ocasiones la Corona había reiterado la prohibición de que las autoridades nombradas por el rey se dedicasen al cultivo. Ver: Provisão para os governadores do Maranhão nem outra pessoa algua ocuparem os Índios forros nos mezes de dezembro, janeiro, maio e junho nem na lavra do tabaco. Lisboa, 9-IX-1648. Anais da Biblioteca Nacional, vol. 66 (1948), p. 19; Provisão sobre a liberdade e captiveiro do gentio do Maranhão. Lisboa, 17-X-1653. Anais da Biblioteca Nacional, vol. 66 (1948), p. 21; e Ley que se passou pelo Secretario de Estado em 9 de abril de 655 sobre os Indios do Maranhão. Alcântara, 9-IV-1655. Anais da Biblioteca Nacional, vol. 66 (1948), p. 27.

62 Provisão sobre o augmento da agrecultura das baunilhas e cacáo. Lisboa, 1-XII-1677. Anais da Biblioteca Nacional, vol. 66 (1948), p. 42.

63 Para o governador do Maranhão. Sobre se lhe dizer a forma em que se manda tratar da cultura das baunilhas e cacao. Lisboa, 1-XII-1677. Anais da Biblioteca Nacional, vol. 66 (1948), p. 41; Para os officiaes da Camara do Pará. Sobre a cultura do Cacáo, e baunilhas. Lisboa, 8-XII-1677. Anais da Biblioteca Nacional, vol. 66 (1948), pp. 44-45; Para o governador do Maranhão. Planta de Cacao e Baonilha. Lisboa, 19-VIII1678. Anais da Biblioteca Nacional, vol. 66 (1948), p. 46; Para o provedor da Fazenda do Maranhão. Planta do Cacáo e Baunilhas. Lisboa, 19-VIII-1678. Anais da Biblioteca Nacional, vol. 66 (1948), pp. 46-47; Para o governador do Maranhão. Sobre o mesmo. Lisboa, 13-I-1679. Anais da Biblioteca Nacional, vol. 66 (1948), p. 47; Para o provedor da Fasenda do Maranhão. Sobre o mesmo. Lisboa, 13-I-1679. Anais da Biblioteca Nacional, vol. 66 (1948), pp. 47-48. Ver también: Sobre os Indios do Maranhaõ. Lisboa, 29-III-1680. ANTT, Conselho Utramarino, Decretos, livro 1, ff. 59v-60.
} 
similares fueron enviadas también al Estado del Brasil, lo que indica el creciente interés de la Corona por los dos productos ${ }^{64}$.

Ya a principios de 1680, se discutía en la Corte otras formas de incentivar el cultivo del cacao. Había llegado a Lisboa un "papel" condenando el monopolio (o estanco) de venta del chocolate en Portugal, que "destruye totalmente" el cacao y vainilla que producía el Estado del Maranhão y Pará. El autor del papel, tal vez el gobernador Inácio Coelho da Silva, condenaba el contrato, firmado años antes por la Corona y mercaderes de Lisboa, por el cual no se podía hacer "chocolate de cacao y vainillas, producidas o venidas de las conquistas de este reino, sin licencia de los contratantes" ${ }^{65}$.

Para el autor anónimo, ese contrato arruinaba a los colonos del Maranhão y Pará ya que en vez de que el cacao y la vainilla se vendieran libremente en Portugal, "por los precios que fueran cómodos", los contratantes determinaban el valor de compra. El texto también defendía que la Corona librase a los productos de derechos de aduana, tal cual se había hecho con otros productos, como el azúcar. Así, concluía el "papel", la "conservación de aquel Estado [de Maranhão y Pará]" estaba en el fin del monopolio del chocolate, la exención de derechos del cacao, y de "todas las nuevas drogas que se descubran".

Por sugerencia del procurador de la Real Hacienda, el texto fue examinado por mercaderes de Lisboa, que condenaron duramente el monopolio y defendían el incentivo a la producción por medio de una reducción de los derechos de aduana. Semejante opinión tenía el propio Consejo Ultramarino, que recomendaba al príncipe acudiese con "remedio conveniente al daño que se puede seguir en la manutención del contrato". Finalmente, por resolución real, el soberano ordenaba al Consejo de Hacienda la extinción del estanco ${ }^{66}$. Más todavía, determinaba que el cacao cultivado, las vainillas y el añil del Estado del Maranhão y Pará no pagasen derechos por seis años, y pagasen medios derechos por más de cuatro años. Ya el cacao silvestre pagaría medios derechos por cuatro años ${ }^{67}$. Estaba clara la política de la Corona en favorecer el cultivo del cacao.

Ya en el propio Estado del Maranhão y Pará, las cosas no iban como esperaba la Corona. En primero lugar, el gobernador, Inácio Coelho da Silva, y el proveedor, Don Fernando Ramírez, claramente no se entendían. En abril de 1681, Coelho da Silva se quejaba de Don Fernando, quien no había tratado de la introducción del "cacao cultivado", como prometido en el "papel que allí ofreció". Según el gobernador o había sido porque encontrase Don Fernando "diferencia entre estas tierras y las de las Indias de Castilla", o porque le pareció que de hecho no le tocaba a él esa función, ya que los padres de la Compañía y algún colono ya lo habían hecho. A seguir, el gober-

\footnotetext{
64 WALKER, 2007, p. 84.

65 Ver: Contrato do estanco da agoa ardente, chocolate, cerueja, rosasolis, cidra, soruetes, limonadas, e mais bebidas desta qualidade, que se fez no Conselho da Fazenda por tempo de noue annos, com Henrique de Borja, Luis de Valença, e seus Companheiros. Lisboa: na Officina de Joam da Costa, 1679, pp. 4-5.

66 Ver: Alphabeto das rezoluções das Consultas do Conselho da Fazenda. Decretos e Alvaras que os Reys de Portugal passaraõ sobre a adminstraçaõ da sua Real Fazenda. Anno de 1705. Biblioteca Nacional de Portugal, Coleção Pombalina, no 178, f. 87v.

67 El "papel”, la consulta del Consejo Ultramarino, los pareceres de los mercaderes y la resolución real están en: Consulta del Consejo Ultramarino. Lisboa, 14-III-1680. AHU, Maranhão (Avulsos), caixa 6, doc. 647.
} 
nador alababa sus propias acciones, incentivando a los colonos a plantar el cacao, incluso con promesas de mercedes reales. Incluso, se había encontrado a nuestro ya conocido João de Ornelas da Câmara, según Coelho da Silva, el "primero que en este Estado le dio principio" al cultivo del cacao, hacía ya más de cinco años ${ }^{68}$.

A pesar de los incentivos de la Corona, no hay duda que la producción del cacao cultivado tardó en establecerse. En septiembre de 1684, el rey escribía al gobernador que no dejase de encomendar a los colonos que cultivasen cacao y vainillas ${ }^{69}$. Dos años más tarde, nuevamente el rey se quejaba que los colonos no mandaban cacao "con tanta abundancia", por lo que le advertía "el cuidado de su cultura, premiándose a los que lo cultivaren" $"$. Solamente a finales de siglo aparecen las primeras noticias positivas. En una petición escrita al Consejo Ultramarino, el representante del Estado del Maranhão y Pará en la Corte finalmente escribía que

la capitanía del Grão-Pará logra hoy la cultura del cacao, estando sus moradores unos y otros con emulación (...) y hay esperanzas de que en esta cultura tendrá la Real Hacienda muchos rendimientos, así en los diezmos como en los derechos ${ }^{71}$.

Por otro lado, las tierras concedidas a colonos por los gobernadores a finales del siglo XVII y principios del siglo XVIII y confirmadas por el rey, mencionaban el cultivo del cacao o la intención de hacerlo. De las 47 tierras de las que tenemos registro, dadas en el Pará, entre 1694 y 1705, en 24 se decía ya plantar cacao ${ }^{72}$ y en seis se solicitaba la tierra para plantar cacao ${ }^{73}$. Como la posesión y uso económico de la tierra era uno de los argumentos más importantes en las colonias portuguesas para que las autoridades concediesen tierras en nombre del rey, podemos inferir que, de hecho, el cultivo del cacao se fue, poco a poco, extendiendo por los ríos de la región.

Todavía, una característica propia del cacao de la Amazonía portuguesa, a diferencia de la producción en las Indias de Castilla, fue la convivencia entre el cultivo y la recolecta de frutos en árboles silvestres, el llamado "cacao bravo", en el vasto interior del territorio, el sertão, por cuyos ríos navegaban portugueses, indios, mestizos, africanos. La bibliografía indica que esta producción fue incluso más importante ${ }^{74}$.

68 Carta de Inácio Coelho da Silva a Dom Pedro II. Belém, 10-IV-1681. AHU, Pará (Avulsos), caixa 3, doc. 190.

69 Para o governador do Maranhão. Lisboa, 2-IX-1684. Anais da Biblioteca Nacional, vol. 66 (1948), pp. 65-66.

70 Para o governador do Maranhão. Sobre a cultura do cacáo e premiar-se os que o cultivarem. Lisboa, 24-XI-1686. Anais da Biblioteca Nacional, vol. 66 (1948), pp. 73-74.

71 El documento está en: Consulta de Consejo Ultramarino. Lisboa, 21-VIII-1699. AHU, Maranhão (Avulsos), caixa 9 , doc. 981 .

72 Los registros no tienen título, razón por la cual indico el libro y número de los folios. ANTT, Chancelaria de Pedro II. Libro 27, ff. 78-79, 87v-88v, 110-111, 112v-113v, 113v-114v, 292v-294 (dos concesiones en el mismo documento), 294-295 (dos concesiones en el mismo documento); libro 28, ff. 27-28, 300v-301v; libro 30, ff. 172-173, 176v-178, 175v-176v, 179-180, 194v-195, 202-202v, 210-211, 232-233; libro 31, ff. 40-41; libro 45, ff. 318-319; libro 55, ff. 111v-112; libro 63, ff. 70-70v, 246v-247.

73 ANTT, Chancelaria de Pedro II. Libro 30, ff. 180v-181, 210-211, 343v-345; libro 31, ff. 63-64, 88v-89v; libro 44, ff. 340v-341.

74 Dias, 1961, p. 27; Gross, 1969, p. 10; Alden, 1976, p. 115. Ver también: Roller, 2010. 
Infelizmente, la ausencia de datos sistemáticos sobre las exportaciones de cacao hasta los años 1730 nos impide cualquier comparación más clara entre los dos productos ${ }^{75}$.

\section{CONCLUSIONES}

En estas páginas se trató de mostrar cómo la industria del cacao amazónico, el "cacao de Marañón" como se llegó a llamar en España, se tiene que comprender a partir de las múltiples conexiones que enlazaban a las conquistas ibéricas. En el desarrollo del cultivo del cacao en la Amazonía portuguesa, la Monarquía Hispánica tuvo un papel fundamental durante y después de su existencia. La experiencia de la unión dinástica puso en marcha conexiones entre el mundo portugués y el mundo del cacao hispánico que fueron después importantes para definir la manera cómo la corona portuguesa organizó los primeros intentos de explotación del cacao "manso". En ese sentido, los caminos que nos ayudan a comprender las dinámicas sociales y económicas de la Amazonía portuguesa colonial no necesariamente están en el mundo portugués. El texto quiere llamar la atención no tanto para una historia comparativa; pero sí para una perspectiva que apuesta en las implicaciones de las relaciones que articulaban las conquistas ibéricas de América durante el siglo XVII y parte del siglo XVIII, dejadas de lado, en gran medida, por una historiografía demasiado centrada en una historia limitada a las fronteras del actual Estado nacional.

\section{REFERENCIAS BIBLIOGRÁFICAS}

AcEvedo Marin, Rosa Elizabeth - Gomes, Flavio

2003 "Reconfigurações coloniais: tráfico de indígenas, fugitivos e fronteiras no Grão-Pará e Guiana francesa (séculos XVII e XVIII)”. Revista de História. São Paulo, vol. 149, pp. 69-107.

ACuÑa, Cristóbal de (SJ)

1641 Nuevo descubrimiento del gran rio de las Amazonas. Madrid. Imprenta del Reyno.

ALDEN, Dauril

1976 "The significance of cacao production in the Amazon region during the late colonial period: an essay in comparative economic history". Proceedings of the American Philosophical Society. Philadelphia, vol. 120, n 2, pp. 103-135.

1996 The making of an enterprise. The Society of Jesus in Portugal, its empire and beyond, 1540-1750. Stanford. Stanford University Press.

Alencastro, Luiz Felipe de

2000 O trato dos viventes. Formação do Brasil no Atlântico sul. São Paulo. Companhia das Letras.

Almeida, Luís Ferrand de

1995 "Aclimatação de plantas do Oriente no Brasil durante os séculos XVII e XVIII". En: Páginas dispersas. Estudos de história moderna de Portugal. Coimbra. IHES/FLUC, pp. 59-129.

\footnotetext{
75 E incluso, después de 1730, no hay detalles en cuanto al hecho de ser cacao "manso" o "bravo".
} 
Arcila Farías, Eduardo

1946 Economía colonial de Venezuela. México. Fondo de Cultura Económica.

1950 Comercio entre Venezuela y México em los siglos XVII y XVIII. México. El Colegio de México.

Arenz, Karl-Heinz

2010 De l'Alzette à l'Amazone. Jean-Philippe Bettendorff et les jésuites en Amazonie portugaise (1661-1693). Saarbrücken. Editions Universitaires Européennes.

BERGMAN, John F.

1969 "The distribution of cacao cultivation in pre-Columbian America". Annals of the Association of American Geographers. Washington, vol. 59, nº 1, pp. 85-96.

Bouza Álvarez, Fernando

2000 Portugal no tempo dos Filipes. Política, cultura, representações (1580-1668). Lisboa. Edições Cosmos.

BRAUDEL, Fernand

1979 Civilisation matérielle, économie et capitalisme, XVte-XVIII siècle. Paris. Armand Collin, vol. I.

Caetano, Antonio Filipe Pereira

2011 “"Para aumentar e conservar aquelas partes...': Conflitos dos projetos lusoamericanos para uma conquista colonial (Estado do Maranhão e Grão-Pará, séculos XVII-XVIII)". Revista Estudos Amazônicos. Belém, vol. VI, nº 1, pp. 1-20.

CARDim, Pedro

2004 "O governo e a administração do Brasil sob os Habsburgo e os primeiros Bragança". Hispania. Madrid, vol. 64, nº 216, pp. 117-156.

CARDoso, Alírio Carvalho

2010 "Outra Ásia para o império: fórmulas para a integração do Maranhão à economia oceânica (1609-1656)". En Chambouleyron - Ruiz-Peinado Alonso, T(r)ópicos de história: gente, espaço e tempo na Amazônia (séculos XVII a XXI). Belém. Açaí, pp. 9-26.

2012 Maranhão na Monarquia Hispânica: intercâmbios, guerra e navegação nas fronteiras das Índias de Castela (1580-1655). Salamanca. Tesis Doctoral, Universidad de Salamanca.

CARdoso, Ciro Flamarion

1984 Economia e sociedade em áreas coloniais periféricas: Guiana francesa e Pará (1750-1817). Rio de Janeiro. Graal.

Chambouleyron, Rafael

2005 "Opulência e miséria na Amazônia seiscentista”. Raízes da Amazônia. Manaus, vol. I, não ${ }^{\circ} 1$, pp. 105-124.

2007 “As especiarias da Amazônia”. BR História. São Paulo, ano 1, n 1, pp. 70-74.

2010 Povoamento, ocupação e agricultura na Amazônia colonial (1640-1706). Belém. Açaí.

DiAs, Manuel Nunes

1961 "O cacau brasileiro na economia mundial - subsídios para sua história”. Stvdia. Lisboa, vol. 8, pp. 7-93.

FATTACCIU, Irene

2012 "Atlantic History and Spanish consumer goods in the 18th century: The assimilation of exotic drinks and the fragmentation of European identities". Nuevo Mundo Mundos Nuevos, www.nuevomundo.revues.org/63480 
FERRY, Robert

1989 The Colonial Elite of Early Caracas: Formation and Crisis, 15671767. Berkeley. University of California Press.

2006 “Trading cacao: a view from Veracruz, 1626-1645”. Nuevo Mundo - Mundos Nuevos, http://nuevomundo.revues.org/document1430.html

Furtado, Celso

1987 Formação econômica do Brasil [1959]. 22ª edición. São Paulo. Companhia Editora Nacional.

Gomes, Flávio dos Santos

2011 “Africanos, tráfico atlántico y cimarrones en las fronteras entre la Guyana francesa y la América portuguesa, siglo XVIII". Fronteras de la Historia. Bogotá, vol. 16, nº 1, pp. 152-175.

Gross, Sue Anderson

1969 The economic life of the Estado do Maranhão e Grão Pará, 1686-1751. New Orleans. Tesis Doctoral, Tulane University.

GruZinski, Serge

2001 "Les mondes mêlés de la Monarchie Catholique et autres "connected histories"”. Annalaes. Histoire, Sciences Sociales. Paris, 56e année, n 1, pp. 85-117.

2004 Les quatre parties du monde: historie d'une mondialisation. Paris. Éditions de La Martinière.

GuZmán, Décio de Alencar

2006 "Encontros circulares: guerra e comércio no Rio Negro (Grão-Pará), séculos XVII e XVIII". Anais do Arquivo Público do Pará. Belém, vol. 5, tomo 1, pp. 139-165.

HARWICH, Nikita

1995 "Le chocolat et son imaginaire, XVIème-XVIIIème siécles: le monde américain dans une tasse". Jahrbuch für Geschichte von Staat, Wirtschaft und Gesellschaft Lateinamerikas. Colonia, tomo 32, pp. 261-293.

2005 “Le cacao vénézuélien: une plantation à front pionnier". Caravelle. Toulouse, $\mathrm{n}^{\circ} 85$, pp. 17-30.

Heriarte, Mauricio de

1874 Descripção do Estado do Maranhão, Pará, Corupá e rio das Amazonas [años 1660]. Edición preparada por Francisco Adolfo de Varnhagen. Viena. Imprensa do filho de Carlos Gerold.

HernÁndez Jaimes, Jesús

2008 "El fruto prohibido. El cacao de Guayaquil y el mercado novohispano, siglos XVIXVIII”. Estudios de Historia Novohispana. México D.F., nº 39, pp. 43-79.

Hordes, Stanley M

1982 "The Inquisition as Economic and Political Agent: The Campaign of the Mexican Holy Office against the Crypto-Jews in the Mid-Seventeenth Century". The Americas. Washington, vol. 39, $\mathrm{n}^{\circ} 1$, pp. 23-38.

Hulsman, Lodewijk

2011 "Swaerooch: o comércio holandês com índios no Amapá (1600-1615)". Revista Estudos Amazônicos. Belém, vol. VI, nº 1, pp. 178-202.

LAPA, José Roberto do Amaral

1973 “O problema das drogas orientais". En Economia colonial. São Paulo. Perspectiva, pp. 111-140. 
LeITE, Serafim

1943 História da Companhia de Jesus no Brasil. Lisboa - Rio de Janeiro. Portugália - INL, vol. IV.

LEÓn BorJa, Dora - SzÁsZdi NAGY, Ádám

1964 “El comercio del cacao de Guayaquil”. Revista de Historia de América. San José, nos 57-58, pp. 1-50.

Livi BACCI, Massimo

2012 Amazzonia. L'impero dell'acqua, 1500-1800. Bologna. Il Mulino.

MACLEOD, Murdo J.

2008 Spanish Central America: a socioeconomic history, 1520-1720 [1973]. Austin. University of Texas Press.

MaCLEOD, Philip

1996 “Auge y estancamiento de la producción de cacao en Costa Rica, 1660-1695". Anuario de Estudios Centroamericanos. San José, vol. 22, nº 1, pp. 83-107.

Marques, Guida

2009 L'invention du Brésil entre deux monarchies. Gouvernement et pratiques politiques de l'Amérique portugaise dans l'union ibérique (1580-1640). Paris. Tesis Doctoral. École des Hautes Études en Sciences Sociales.

2010 "Entre deux empires: le Maranhão dans l'Union ibérique (1614-1641)". Nuevo Mundo - Mundos Nuevos, http://nuevomundo.revues.org/59333

Newson, Linda - Minchin, Susie

2007 From capture to sale: the Portuguese slave trade to Spanish South America in the early seventeenth century. Leiden. Brill.

Norton, Marcy

2006 "Tasting empire: chocolate and the European internalization of Mesoamerican aestethics". The American Historical Review. Chicago, vol. 111, n 3, pp. 660-691.

PIÑERO, Eugenio

1988 "The cacao economy in eighteenth-century province of Caracas and the Spanish cacao market". Hispanic American Historical Review. Durham, NC, vol. 68, $\mathrm{n}^{\mathrm{o}} 1$, pp. 75-100.

PrADO JÚNIOR, Caio

1987 História econômica do Brasil [1945]. 35ª edición. São Paulo. Brasiliense.

ReIs, Arthur Cezar Ferreira

1993 A politica de Portugal no vale amazônico [1940]. 2ª edición. Belém. Secult.

Ricci, Magda

2003 "O fim do Grão-Pará e o nascimento do Brasil: movimentos sociais, levantes e deserções no alvorecer do novo Império (1808-1840)". En: Priore - GoMES, Os senhores dos rios. Amazônia, margens e histórias. Rio de Janeiro. Campus, pp. 165193.

RoLLer, Heather Flynn

2010 "Colonial collecting expeditions and the pursuit of opportunities in the Amazonian sertão, c. 1750-1800". The Americas. Washington, vol. 66, n 4, pp. 435-467.

Rosés Alvarado, Carlos

1982 "El ciclo del cacao en la economía colonial de Costa Rica, 1650-1794”. Mesoamérica. New Orleans, vol. 3, nº 4, pp. 247-278. 
Ruiz-Peinado Alonso, José Luis

2012 "Entre aguas, fronteras de la Amazonía”. Clio - Revista de Pesquisa Histórica. Recife, vol. 30, n 1, pp. 1-21.

SAntos PÉrez, José Manuel

2012 “A estratégia dos Habsburgo para a América portuguesa. Novas propostas para um velho assunto". En Almeida - Silva - Silva - Souza, Políticas e estratégias administrativas no mundo atlântico. Recife. EdUFPE, pp. 247-253.

SchAUB, Jean-Frédéric

2001 Portugal na Monarquia Hispânica (1580-1640). Lisboa. Livros Horizonte.

SCHWARTz, Stuart

1998 "O Brasil colonial, c.1580 - c.1750: as grandes lavouras e as periferias”. En BETHELL, História da América Latina [1984]. São Paulo - Brasília. EdUSP - Fundação Alexandre Gusmão, 1998, vol. II, pp. 339-421.

SiMONSEN, Roberto

1937 História econômica do Brasil. São Paulo. Companhia Editora Nacional.

SiLva, Kalina Vanderlei

2012 “A América açucareira portuguesa no governo de Felipe IV de Espanha”. En AlmeIDA - Silva - Silva - Souza, Políticas e estratégias administrativas no mundo atlântico. Recife. EdUFPE, pp. 255-270.

SODRÉ, Nelson Werneck

1964 Formação histórica do Brasil [1962]. $3^{\text {a }}$ edición. São Paulo. Brasiliense.

StUdNicki-Gizbert, Daviken

2001 Capital's Commonwealth: The World of Portugal's Atlantic Merchants and the Struggle over the Nature of Commerce in the Spanish Empire, 1492-1640. New Haven. Tesis Doctoral. Yale University.

Tous, Meritxell

2011 "Cacao y encomienda en la Alcaldía Mayor de Sonsonate, siglo XVI". Anuario de Estudios Americanos. Sevilla, vol. 68, nº 2, pp. 513-537.

VALLADARES RAmírez, Rafael

1993 "El Brasil y las Indias españolas durante la sublevación de Portugal (1640-1668)". Cuadernos de Historia Moderna. Madrid, nº 14, pp. 151-172.

VILA VILAR, Enriqueta

1973 "Los asientos portugueses y el contrabando de negros". Anuario de Estudios Americanos. Sevilla, vol. 30, pp. 557-599.

VILARDAGA, José Carlos

2010 São Paulo na órbita do império dos Filipes: conexões castelhanas de uma vila da América portuguesa durante a União Ibérica (1580-1640). São Paulo. Tesis Doctoral. Universidade de São Paulo.

WALKER, Thimoty

2007 "Slave labor and chocolate in Brazil: the culture of cacao plantations in Amazonia and Bahia $\left(17^{\text {th }}-19^{\text {th }}\right.$ centuries)". Food \& Foodways. Londres, vol. 15, n ${ }^{\circ} 1-2, p p$. 75-106.

WHEAT, David

2009 The Afro-Portuguese maritime world and the foundations of Spanish Caribbean society, 1570-1640. Nashville. Tesis Doctoral. Vanderbilt University. 